\title{
Jean-Raymond Fanlo, André Tournon, Formes de millénarisme en Europe à l'aube des temps modernes
}

Paris, Honoré Champion, 2001, 480 p. (Actes du colloque international de l'Association Renaissance, Humanisme, Réforme (Marseille, 10-12 septembre 1998), (coll. « Colloques, congrès et conférences sur la Renaissance ", 25).

Jean Séguy

\section{OpenEdition}

\section{Journals}

Édition électronique

URL : http://journals.openedition.org/assr/1389

DOI : $10.4000 /$ assr. 1389

ISSN : $1777-5825$

Éditeur

Éditions de l'EHESS

Édition imprimée

Date de publication : 1 avril 2003

Pagination : $59-157$

ISBN : 2-222-96732-5

ISSN : 0335-5985

Référence électronique

Jean Séguy, « Jean-Raymond Fanlo, André Tournon, Formes de millénarisme en Europe à l'aube des temps modernes », Archives de sciences sociales des religions [En ligne], 122 | avril - juin 2003, document 122.69, mis en ligne le 10 novembre 2005, consulté le 21 septembre 2020. URL : http:// journals.openedition.org/assr/1389; DOI : https://doi.org/10.4000/assr.1389 
de quelques groupes andins de Cochabamba et La Paz, et des Mojos amazoniens du Beni, en Bolivie.

Les textes rassemblés, bien qu'écrits à partir de la perspective et des préoccupations d'agents de la pastorale catholique, peuvent être utiles pour s'initier à la connaissance de l'histoire et des caractéristiques de la théologie indienne. Ils sont aussi révélateurs des espoirs et des interrogations que suscite cette théologie à l'intérieur de l'Église catholique.

\section{Rodolfo de Roux.}

\subsection{7}

ENCREVÉ (André).

L'Expérience et la foi. Pensée et vie religieuse des huguenots au XIX ${ }^{\mathrm{e}}$ siècle. Genève, Labor et Fides, 2001, 424 p. (coll. « Histoire et société », 42).

A.E. a réuni dans ce volume seize de ses articles et contributions à des ouvrages collectifs, parus entre 1974 et 1997. Certains étaient facilement accessibles, d'autres beaucoup moins, et c'est mettre à la disposition des chercheurs un utile instrument de travail que de relier les textes saillants d'une carrière déjà bien remplie. Plusieurs de ces études ont été en outre allégées et remaniées, ou à l'inverse augmentées, pour tenir compte des progrès de la recherche, et elles ont été retenues et classées ici en fonction d'un projet précis, explicité à la fois dans l'introduction et par le plan. Pour A.E., les historiens se sont beaucoup intéressés à la place des protestants dans le débat politique, mais la vie interne de l'Église a moins fréquemment retenu leur attention. Or si l'on définit la minorité protestante d'abord par sa profession de croyances religieuses et son adhésion à une ecclésiologie, différentes de celles du catholicisme, c'est l'évolution doctrinale, puis la vie religieuse des fidèles, qui doivent retenir l'attention. D'autant que le protestantisme français se trouve, au début du $\mathrm{XIX}^{\mathrm{e}}$ siècle, dans une situation particulière : il sort d'une période séculaire de persécutions ou de clandestinité et il a perdu le contact avec la recherche théologique vivante, telle qu'il pouvait l'abriter au $\mathrm{XVII}^{\mathrm{e}}$ siècle et qu'elle a continué à se développer en Angleterre ou en Allemagne. La réorganisation concordataire ne peut donc lui faire faire l'économie d'une sorte d'apprentissage théologique, à l'école d'une Europe protestante d'où lui viennent à la fois le Réveil et le libéralisme.

A.E. excelle à analyser les débats théologiques qui ont transformé puis divisé le protestantisme français, à partir des années 1850, jusqu'à aboutir au "schisme de fait" de 1872 . On sait que deux camps se sont affrontés : les "évangéliques" ou "orthodoxes", ramenés sous l'influence du Réveil à une théologie calviniste, et les "libéraux", attentifs au travail critique mené dans les universités allemandes, et dont beaucoup allaient rompre avec l'Église au lendemain du synode national de 1872, avant d'entrer en politique, pédagogie ou laïcité. Les deux études qui ouvrent le volume, issues de la Revue d'Histoire Ecclésiastique de 1992 et d'un recueil paru en Grande-Bretagne en 1990, rendront de grands services par le vigoureux panorama qu'elles proposent de l'évolution ecclésiologique et théologique du protestantisme français au XIX ${ }^{\mathbf{e}}$ siècle. On trouve ensuite un certain nombre de portraits, dont ceux des théologiens Edmond Scherer, Timothée Colani, Félix Pécaut, trois libéraux "extrémistes" (un qualificatif un peu... extrémiste, peut-être), l'analyse de crises internes (le synode de 1872, et le problème posé par Maurice Vernes à la Faculté de théologie protestante de Paris en 1876), l'étude des réactions de protestants devant le concile du Vatican ou l'encyclique Rerum novarum, ou encore un utile chapitre sur les bibles et sociétés bibliques dans le protestantisme français, repris du volume Le monde contemporain et la Bible (1985).

Patrick Cabanel.

ESPOSITO (John L.), WATSON (Michael), eds.

Religion and Global Order. Cardiff, University of Wales Press, 2000, 239 p. (index) (coll. "Religion, Culture and Society ») (cf. Arch. supra, pp. 27-30).

FANLO (Jean-Raymond), TOURNON (André), éds.

Formes de millénarisme en Europe à l'aube des temps modernes. Paris, Honoré Champion, 2001, 480 p. (Actes du colloque international de l'Association Renaissance, Humanisme, Réforme (Marseille, 10-12 septembre 1998), (coll. « Colloques, congrès et conférences sur la Renaissance », 25).

Vingt-trois auteurs hautement qualifiés et autant de communications, entourés de remerciements et d'une présentation par A.T. en entrée de jeu, avec - en finale - un index et une table des matières, voici de quoi recomposer l'ouvrage ici recensé. Nous nous permettons quelques remarques générales, à défaut de vingt-trois commentaires successifs et particu- 
larisés : on peut douter d'ailleurs qu'un seul recenseur puisse se montrer compétent sur l'ensemble des cas examinés.

Pourtant nous ferons une exception : pour saluer l'apport de Jean Delumeau, dont la contribution inaugurale permet de traverser l'histoire du millénarisme occidental. On le notera, cette dernière traverse l'histoire du christianisme même, de bout en bout.

Les AA. - et celui de la présentation en particulier - soulignent que les « formes du millénarisme " sont - à s'en tenir à celles que le volume évoque, bien variées. Il est vrai, mais plus d'un parmi les AA. soulignent aussi que, à prendre les choses au sens strict, il existe peu de millénarismes, à l'aune d'Apoc. 20, 1-6 en tout cas. On le concède volontiers. Dès lors, le problème est de savoir quel statut on attribue aux formes - elles-mêmes variées - du joachimisme. Pour l'essentiel, ce sont elles, en effet qui - installant une attente de l'Esprit au lieu d'un règne millénaire du Christ - semblent changer la donne, et justifier que certains commentateurs distinguent en ce recueil entre vrais millénarismes et ... autres (faux ?) millénarismes. Nous permettra-t-on de penser qu'il convient de prendre les choses autrement? La référence à Apoc. 20, 1-6 nous paraît indispensable; mais elle n'épuise pas les formes de l'attente eschatologique des christianismes en leur histoire. C'est à partir d'un type à construire (en histoire et en sociologie, en anthropologie encore...) type général des attentes chrétiennes qu'il convient d'aborder le problème des millénarismes et des formes non millénaristes mais plus ou moins millénarisantes de ces attentes. Dès lors deviendra possible la comparaison des contenus et des effets historiques et sociaux de ces mêmes attentes, et les tentatives d'explication à leur sujet.

Jean Séguy.

\subsection{0}

FILALI (Kamel).

L'Algérie mystique. Des marabouts fondateurs aux khwân insurgés, $X^{\mathrm{e}}-\mathrm{XIX}^{\mathrm{e}}$ siècles. Paris, Publisud, 2002, 215 p. (glossaire, illustr.).

Cet ouvrage retrace le rôle des personnages charismatiques réunis sous le nom global de marabouts (cheikhs et saints locaux, membres de voies soufies, descendants du Prophète,chorfa), dans l'histoire de l'Algérie sous domination ottomane, depuis l'établissement de la Régence d'Alger (1587) jusqu'aux insurrections tribales et confrériques du début du $\mathrm{XIX}^{\mathrm{e}}$ siècle. Après avoir montré l'enracinement progressif des marabouts dans le pays et l'étendue de leurs pouvoirs thaumaturgiques, l'auteur étudie leur part dans l'appel fait aux corsaires turcs pour combattre les menaces de la Reconquista chrétienne jusque sur les villes côtières d'Algérie. Il souligne la diversité de leur adhésion au pouvoir ottoman qui s'établit sur la région et la façon dont, profitant d'une faible pénétration du pouvoir beylical dans les zones rurales, les marabouts devinrent entre celui-ci et les populations des médiateurs indispensables. La période de la domination turque fut donc marquée par un renforcement de la présence et de la richesse des marabouts, et par la fondation de nombreuses zawiyas; mais dès la fin du XVIII ${ }^{\mathrm{e}}$ siècle, l'émergence de regroupements de « frères » (khwan) autour de familles chérifiennes revendiquant souvent également une généalogie mystique dans le cadre de confréries transnationales, commença à saper la légitimité et la puissance des marabouts locaux. Dans un pays affaibli par la débâcle économique et l'anarchie, le pouvoir ottoman fut ébranlé par l'expansion de ces ordres mystiques. Les révoltes auxquelles les khwan participèrent, à la veille et dans les premières années du XIX ${ }^{\mathrm{e}}$ siècle, annoncèrent, malgré leur échec, la chute de la Régence.

Les travaux récents concernant les ordres mystiques en Algérie sont rares; cet ouvrage aurait donc pu contribuer à combler une lacune, d'autant plus qu'il se fonde sur des enquêtes de terrain et l'étude de manuscrits arabes, et qu'il apporte souvent une historiographie précise. Malheureusement les concepts utilisés sont peu assurés, le vocabulaire est souvent imprécis, les sources citées ne font l'objet d'aucune critique, la bibliographie n'apparaît que dans les notes et l'on peut relever de nombreuses inexactitudes. Outre ces manques, ce livre souffre de l'absence totale de tout travail d'édition qui aurait notamment permis de réécrire certains passages parfois à la limite du galimatias.

Liliane Kuczynski.

122.71

FRIDOLIN (Saint-Louis).

Le Vodou haïtien - Reflet d'une société bloquée. Paris, L'Harmattan, 2000, 181 p. (préface de François Houtard) (bibliogr.).

Cet ouvrage est plus un essai sur le vaudou qu'une sociologie de cette religion. Il ne semble pas fondé sur une enquête de terrain originale mais sur des sources secondaires et sur la connaissance immédiate que son auteur a de la société haïtienne, ce qui va d'ailleurs contre la profession de foi durkheimienne annoncée en introduction. L'A. n'établit aucune distinction 